\title{
STOKES-ADAMS ATTACKS DUE TO TOXOPLASMA MYOCARDITIS
}

BY

\author{
J. CHARLES SHEE \\ From The Central Hospital, Bulawayo, Southern Rhodesia
}

When a physician is confronted with a patient suffering from heart failure of obscure æatiology, toxoplasmosis is one of the possible causes to be considered. The difficulties of diagnosis are considerable, and usually the elucidation of the case must rest on the indirect evidence of the complement fixation test (c.f.t.) and the Sabin-Feldman dye test.

Therefore, unless the diagnosis is considered and specifically tested for, it will not be arrived at during the life of the patient.

\section{Case History}

The patient, a white woman, aged 40, born in Southern Rhodesia, had three healthy children. She had no past history of significant illness and was referred in January 1962, for an opinion as to the nature of sudden attacks of loss of consciousness, from which she had been suffering for four months. There had been eight such major attacks, usually occurring at the onset of a menstrual period. The attacks occurred irrespective of whether the patient was in the erect or recumbent position, and, from the description of an onlooker, resembled epilepsy, but there had never been any tongue-biting or urinary incontinence. She would recover consciousness after about three minutes and usually had a severe headache for the rest of the day. She had cut her head badly in falling during one attack. She had also experienced several attacks of "light-headedness" without loss of consciousness. During the time in whick the attacks had occurred she had felt very tired and rather breathless, but had continued with her profession of school-teaching.

On examination she was a well-made woman, with a rather pale complexion. Attention was focused on her cardiovascular system by the presence of a noticeably faint first heart sound and wide splitting of the second sound. An electrocardiograph showed the presence of right bundle-branch block, with a P-R interval of $0.24 \mathrm{sec}$. (see Fig. 1). The possibility of intermittent complete heart-block with ventricular slowing was considered. That night she was seen by her family physician in a typical Stokes-Adams seizure, and was admitted to hospital as an emergency case. Apical rates as low as $15 / \mathrm{min}$. were noted in hospital on the night of admission.

The results of investigations instituted on admission are as follows.

Sedimentation rate (Wintrobe one hour), $15 \mathrm{~mm}$.; antistreptolysin $O$ titre, 12 Todd units; serum cholesterol, $225 \mathrm{mg} . / 100 \mathrm{ml}$.; throat swabs, negative for K.L.B.; rickettsial agglutination tests were negative for $R$. prowazeki, $R$. mooseri, $R$. ricketsii, $R$. akari, and $R$. burneti. The Kahn reaction, using standard antigen, was negative. The $S$. duttoni (relapsing fever) complement-fixation test was negative. The Bilharzial complement-fixation test was negative. Complement-fixation tests for L. canicola, L. icterohamorrhagia, and $L$. pomona were negative. Throat washings and stools were cultured and also inoculated into baby mice, with no recovery of virus. A biopsy of skeletal muscle showed no evidence of amyloidosis or pseudocysts of toxoplasma. A complete blood count was normal.

A teleradiograph showed a full-sized heart, but probably within normal limits (C.T. ratio $50 \%$ ).

Course and Treatment. On the day after admission an electrocardiograph showed 2:1 heart block with a P-R interval of $0.36 \mathrm{sec}$. in the conducted beats (Fig. 2A). The patient was therefore given ephedrine mg. 60 every eight hours by mouth, and an intramuscular injection of $40 \mathrm{mg}$. of a depot preparation of corticotrophin daily. This produced immediate improvement in the intracardiac conduction, and there were no StokesAdams attacks thereafter. If the corticotrophin was omitted for 24 hours there was deterioration (see Fig. 2B and C). 


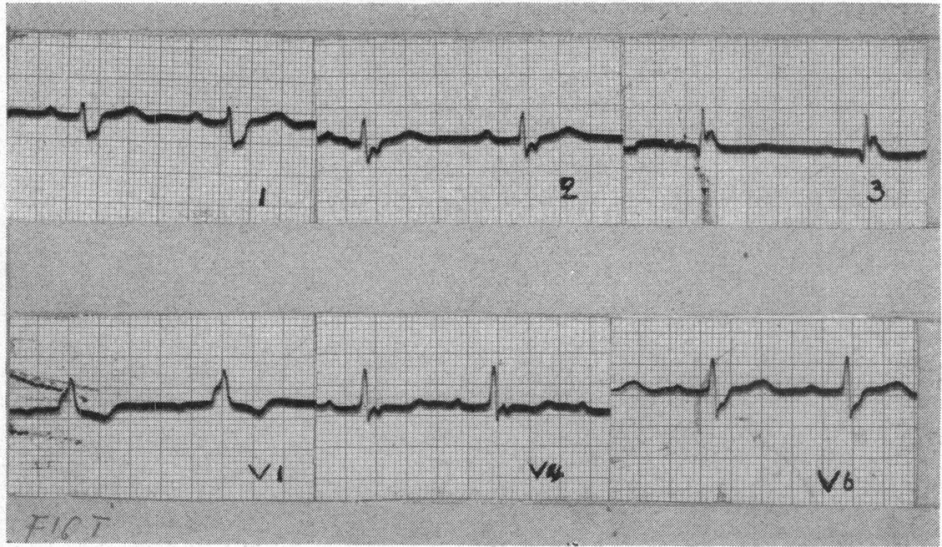

FIG. 1.-Selected leads from electrocardiograph when patient was first seen, showing right bundle-branch block and a P-R interval of 0.24 sec.

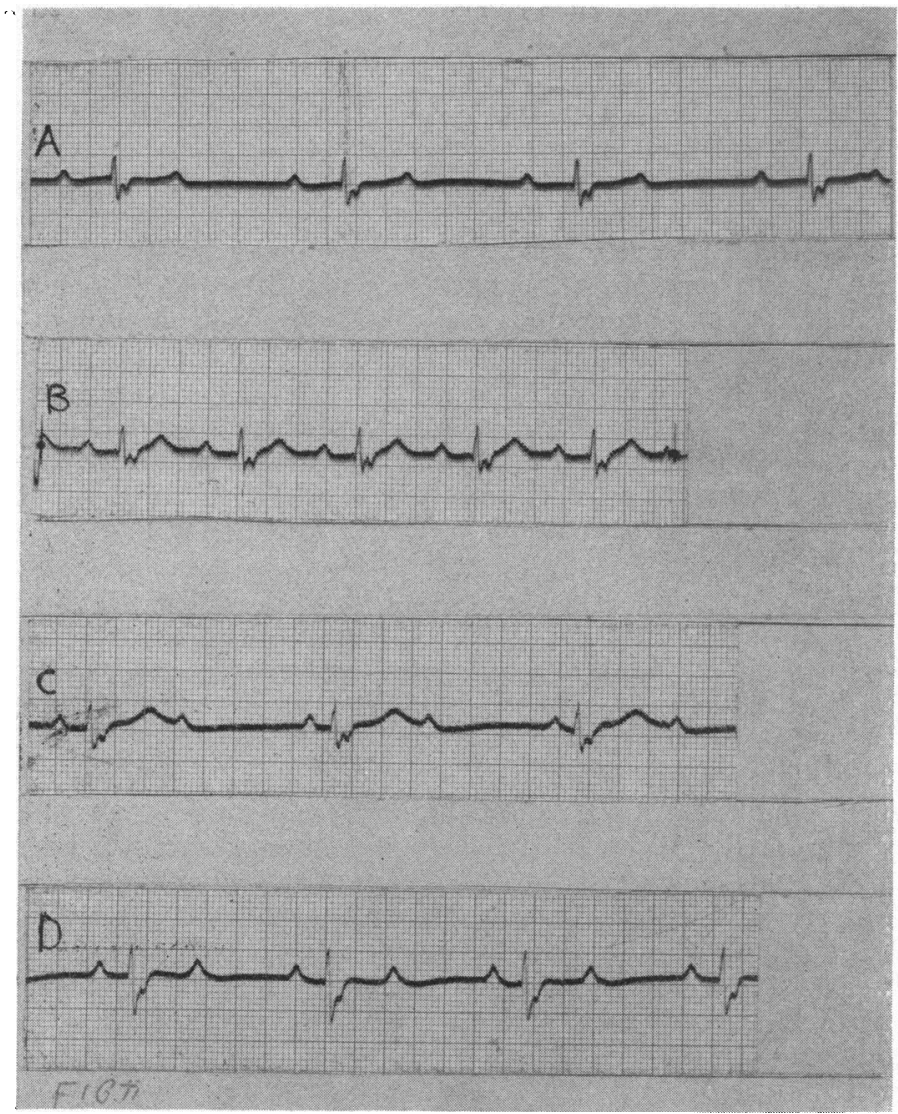

FIG. 2.-All tracings from lead II. (A) Tracing taken February 1, 1962. There is $2: 1$ heart block, and conducted beats show a $\mathbf{P}-\mathbf{R}$ interval of $0.36 \mathrm{sec}$. (B) Taken on March 13, 1962, while the patient was receiving 40 units of corticotrophin gel daily, all beats are conducted, the P-R interval is $0.24 \mathrm{sec}$. (C) Two-one heart block on March 14, 1962, after the omission of corticotrophin gel for 24 hours. (D) Tracing taken on May 29, 1962, four weeks after completion of antitoxoplasma treatment ;2:1 atrioventricular block.
The patient was apyrexial until March 16 (six weeks after admission), when she developed a pulmonary embolus originating in a right internal saphenous thrombophlebitis. She was thereupon put on anticoagulant therapy.

At this stage the diagnostic features of the case were reviewed. Toxoplasma myocarditis had been considered in the differential diagnosis at an early stage, and specific serum tests asked for. It was now discovered that through an oversight they had not been done, and they were again requested.

On March 31, the complementfixation test for toxoplasma gondii was negative, and on April 2 the Sabin-Feldman dye test was positive in a titre of $1: 64$. At this stage the patient was put on pyrimethamine, $25 \mathrm{mg}$., daily and sulphamethoxypyridazine, $0.5 \mathrm{~g}$., twice daily. This treatment was continued for 28 days. On April 18 the toxoplasma complementfixation test was positive at a titre of $1: 8$. The Sabin-Feldman dye test on the same day gave a similar reading to that of April 2. These findings were interpreted by the South African Institute of Medical Research as follows.

"This result (Sabin-Feldman) indicates that this patient has had toxoplasmosis. The titre is not very high but taken in conjunction with the positive result of the c.f.t. the findings suggest that the infection has recently been active."

On May 7, the c.f.t. was no longer positive, which meant that the infection was probably no longer active.

The patient began to feel better almost at once when started on pyrimethamine and sulphonamide, and was allowed out of bed for the first time on April 5. On the same day the corticotrophin injections were stopped, as was oral ephedrine and anticoagulants.

Initially the patient remained in sinus rhythm with a P-R inter- 
val varying between 0.23 and $0.26 \mathrm{sec}$.; however, by April 12 she had relapsed into $2: 1$ atrio-ventricular block, with a ventricular rate of 45 a minute, and a tracing taken in May showed this rhythm (Fig. 2D). At this stage the patient was up and about her home for most of the day, but breathless on exertion. There had been no Stokes-Adams attacks since her admission to hospital four months earlier.

\section{Discussion}

This patient suffered from a cardiopathy of obscure provenance, which presented with StokesAdams attacks. There is strong serological evidence that an active toxoplasma infection was the cause of her illness. In a search for other cases in the family, her husband and three children had their chests and skulls radiographed; these pictures showed no cardiac enlargement nor intracranial calcifications, and the complement-fixation test was negative in the husband, two children, and the family cat, it was anticomplementary in the other child and the family dog. Electrocardiographs of the husband and three children were normal.

It is interesting to note that three of the four cases reported by Paulley et al. (1956) had bundlebranch block, and the case reported here reinforces the suggestion of these workers that toxoplasma should be suspected in all forms of obscure myocarditis.

It is well established that corticotrophin and corticosteroids are often efficacious in improving conduction in heart block from varying causes (Lichfield, Manley, and Polak, 1958; Aber and Wyn Jones, 1960, and others). Corticotrophin appeared to have a favourable effect in the case reported. The specific therapy for toxoplasmosis with pyrimethamine and sulphonamide is more difficult to assess. The patient certainly felt and looked better when started on the drugs. Initially there appeared to be a favourable effect on conduction, and sinus rhythm was maintained for one week after stopping corticotrophin; however 2:1 heart block then recurred. Further steroids or ephedrine have not been given, and so far there has been no recurrence of Stokes-Adams attacks. However, if the histological changes bear any resemblance to those illustrated in the article by Paulley $e t$ al. (1956), it is scarcely surprising that there is residual conduction defect.

This appears to be the first case of toxoplasmosis reported from the Rhodesias.

\section{Summary}

A patient with toxoplasma myocarditis, presenting with Stokes-Adams attacks, is described. Investigations, clinical course, and treatment are discussed.

My thanks are due to Dr. J. Wakeford who referred the patient; to the South African Institute of Medical Research for the toxoplasma serological tests, and for the relapsing fever, leptosperal, and viral tests; and to Doctor P. Barnard for the histological examination of the muscle biopsy and for numerous other pathological tests; and to Dr. L. A. G. Davidson for his interest and advice.

\section{References}

Aber, C. P., and Jones, E. W. (1960). Brit. Heart J., 22, 723.

Litchfield, J. W., Manley, K. A., and Polak, A. (1958). Lancet, 1, 935.

Paulley, J. W., Jones, R., Green, W. P. D., and Kane, E. P. (1956). Brit. Heart J., $18,55$. 